\title{
STRUCTURES OF SINGLE-STAGE AND HIGH POWER FACTOR ELECTRONIC BALLASTS INTEGRATING THE BOOST AND BALLAST INDUCTORS
}

\author{
*Claudinor B. Nascimento, **Marcos A. I. Martins, *Mauricio S. Kaster, **Arnaldo J. Perin \\ *Universidade Tecnológica Federal do Paraná - Ponta Grossa \\ Av. Monteiro Lobato Km 04 - CEP 840116-180, Ponta Grossa - PR. \\ ** INEP - Instituto de Eletrônica de Potência \\ Departamento de Engenharia Elétrica \\ Universidade Federal de Santa Catarina \\ CEP 88040-970, C.P. 5119, Florianópolis - SC \\ *claudinor@utfpr.edu.br,**izumidamarcos@hotmail.com, *mkaster@utfpr.edu.br,**arnaldo.perin@inep.ufsc.br
}

\begin{abstract}
This paper presents a new family of high power factor for electronic ballasts applied to fluorescent lamps. From the proposed structures, two topologies are presented without the ballast inductor, because the boost inductor, in addition to performing power factor correction, also has the function of limiting and stabilizing the lamp current, besides making it to start. The main characteristics of these topologies are the reduction in the production costs owing to fewer components, the low harmonic distortion in the input current, the lower current in the switches, and the lower DC bus voltage. To verify the proposed design methodology and to provide the condition of unity power factor and stabilization of the lamp current, the experimental results of one prototype is presented.
\end{abstract}

Keywords - Electronic ballast, Fluorescent lamps, High power factor, Charge pump.

\section{INTRODUCTION}

Recently, the issue of quality in the electrical energy delivered by electricity distribution systems is gaining attention, mainly owing to energy standards requirements that regulate the electro-electronic equipments. Several of such equipments employ an electronic converter that transforms the energy from AC power supply to different shapes and levels [1]. The majority of converters, for mere economic reasons, spawn distortions to the AC grid voltage waveform, because current waveform is not sinusoidal. In low-power applications, as in the case of lighting systems, the use of new techniques that perform power-factor correction with the objective of minimizing harmonic content while maintaining a near-unity power factor is very attractive [2]-[4]. This is even more important if the cost is kept low.

The use of electronic ballasts operating at high frequencies is clearly attractive owing to several advantages, such as lower energy consumption, higher lighting efficiency $(\mathrm{lm} / \mathrm{W})$, reduced magnetic elements, and absence of audible noise and stroboscopic effect [4].

With the objective of reducing implementation costs, usually single-stage topologies are used, i.e., the inverter and

Manuscript received on $01 / 10 / 2012$. Revised on $17 / 01 / 2013$ and on $25 / 02 / 2013$. Accepted for publication in 26/02/2013 to Special Session by recommendation for the Special Editors Ricardo Nederson do Prado e Pedro F. Donoso-García.
PFC stages of the electronic ballast operate in an integrated design [5]-[16].

In fact, one of the most efficient and widely employed techniques is known as Charge Pump, which achieves $\mathrm{AC}-$ DC conversion and power-factor correction in a single stage [9]. This work presents a new family of electronic ballasts that are based on this concept. The proposed structures represent a highly viable solution to a great portion of the electric energy market share, which holds around $20 \%$ of the total energy consumed by artificial lighting power supplies [17].

\section{TOPOLOGY EVOLUTION}

The family of electronic ballasts presented in [10] is based on the Voltage Source-Charge Pump Power Factor Correction (VS-CPPFC) concept [9], which, although having a reduced number of components, still exhibits low efficiency and high DC bus voltage as disadvantages, limiting its use in low-power applications, mainly in compact fluorescent lamps. With the aim of achieving an improved efficiency as well as reduced DC bus voltage, the topologies proposed in this paper exhibit the characteristic of current source output, i.e., Continuous Input Current - Charge Pump Power Factor Correction (CIC-CPPFC) [11].

Figure 1(a) shows the proposed CIC circuit presented in [12] and [11]. It can be observed that besides the input boost inductor $L_{\text {in }}$, an $L C$ filter is needed to realize the powerfactor correction. In the topology presented in [13] and [7], illustrated in Figure 1(b), the DC bus diode $D_{\mathrm{y}}$ is withdrawn. As a consequence, capacitor $C_{\mathrm{P}}$ is connected in parallel to one of the rectifier bridge diodes that must be fast, because they produce the "dither" effect [18]-[19]. To turn the topology into a symmetric one, two capacitors $C_{\mathrm{P} 1}$ and $C_{\mathrm{P} 2}$ have been used. Such symmetry results in a better energy distribution between the capacitors of the circuit, allowing a lower DC bus voltage and enhancing the power factor by the reduction in the amplitudes of the high-frequency components. Figure 1(c) shows the topology of a CIC electronic ballast published in [14], where, through some modifications, the structures shown in this paper are derived.

In Figure 2(a), a structure where the capacitors $C_{\mathrm{f} 1}$ and $C_{\mathrm{f} 2}$, besides working as input filters and also working as resonant tank circuit capacitor $C_{\mathrm{d}}$, is proposed. The removal of boost inductors $L_{\mathrm{in} 1}$ and $L_{\mathrm{in} 2}$ obligates a filter inductor $L_{\mathrm{f}}$ $\left(\mathrm{L}_{\mathrm{f} 1}+\mathrm{L}_{\mathrm{f} 2}\right)$ to be added, as shown in Figure 2(b). The $L_{\mathrm{in} 1}$ and 
$L_{\text {in2 }}$ inductors of Figure 2(a) do not need to be coupled. By employing the dual boost inductors, it is possible to move out the ballast inductor $L_{\mathrm{B}}$, resulting in the circuit of Figure 2(c). In this case, inductors $L_{\mathrm{in} 1}$ and $L_{\mathrm{in} 2}$ operate with several different functions, such as input filter along with capacitors $C_{\mathrm{f} 1}$ and $C_{\mathrm{f} 2}$, current limiter (ballast), and lamp starter.
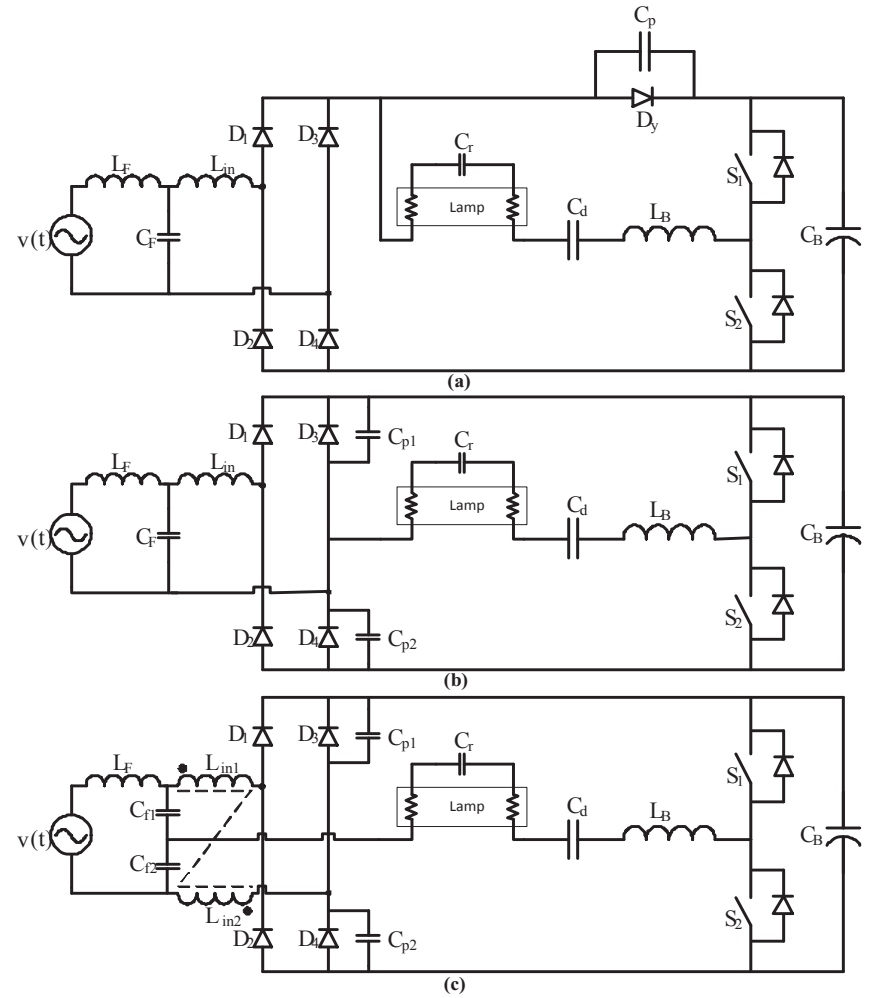

Fig. 1. (a) Topology based on Moisin's (1997) work [12]; (b) Topology presented by Pereira (2004) [13]; (c) Topology presented by Nascimento (2005) [14].
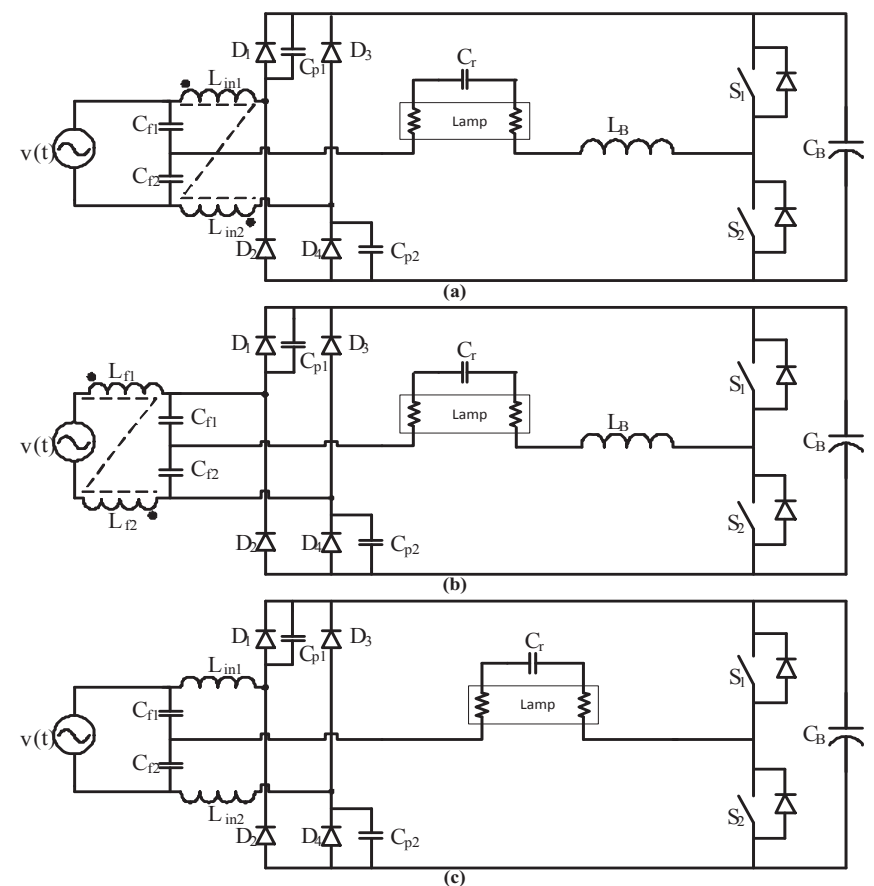

Fig. 2. Proposed topologies 1: (a) without capacitor $C_{\mathrm{d}}$ and without input filter inductor $L_{\mathrm{f}}$; (b) without capacitor $C_{\mathrm{d}}$ and without boost inductors $L_{\mathrm{in} 1}$ and $L_{\mathrm{in} 2}$; (c) without capacitor $C_{\mathrm{d}}$ and without ballast inductor $L_{\mathrm{B}}$.
From the proposed topologies, mathematical analysis and experimental results of structure in Figure 2(c) can be presented, because it is a structure that integrates the resonant tank with the PFC stage, as inductors $\mathrm{L}_{\mathrm{in} 1}$ and $\mathrm{L}_{\mathrm{in} 2}$, together with capacitors $\mathrm{C}_{\mathrm{f} 1}, \mathrm{C}_{\mathrm{f} 2}$, and $\mathrm{C}_{\mathrm{r}}$, perform the role of limiting the lamp starting current as well as power-factor correction of the electronic ballast.

It can be observed that the topologies proposed in Figure 2 can feed one or more lamps, because they have connection conditions at the midpoint between the capacitors $C_{\mathrm{f} 1}$ and $C_{\mathrm{f} 2}$. However, with the midpoint division, one can obtain another set of topologies, as shown in Figure 3. In this case, the operation of these structures is constrained to the use of two lamps.

Figure 3(a) shows the circuit without capacitors $C_{\mathrm{f} 1}$ and $C_{\mathrm{f} 2}$ and ballast inductors $L_{\mathrm{B} 1}$ and $L_{\mathrm{B} 2}$. After the direct connection of the charge-pump capacitors, $C_{\mathrm{p} 1}$ and $C_{\mathrm{p} 2}$, between the power supply $v(t)$ and the rectifier bridge, it is possible to couple inductors $L_{\mathrm{in} 1}$ and $L_{\mathrm{in} 2}$, as stated in Figure 3(b). By removing $L_{\mathrm{in} 1}$ and $L_{\mathrm{in} 2}$, one can obtain the topology shown in Figure 3(c). In this case, a filter inductor must be used, which does not need to be coupled.
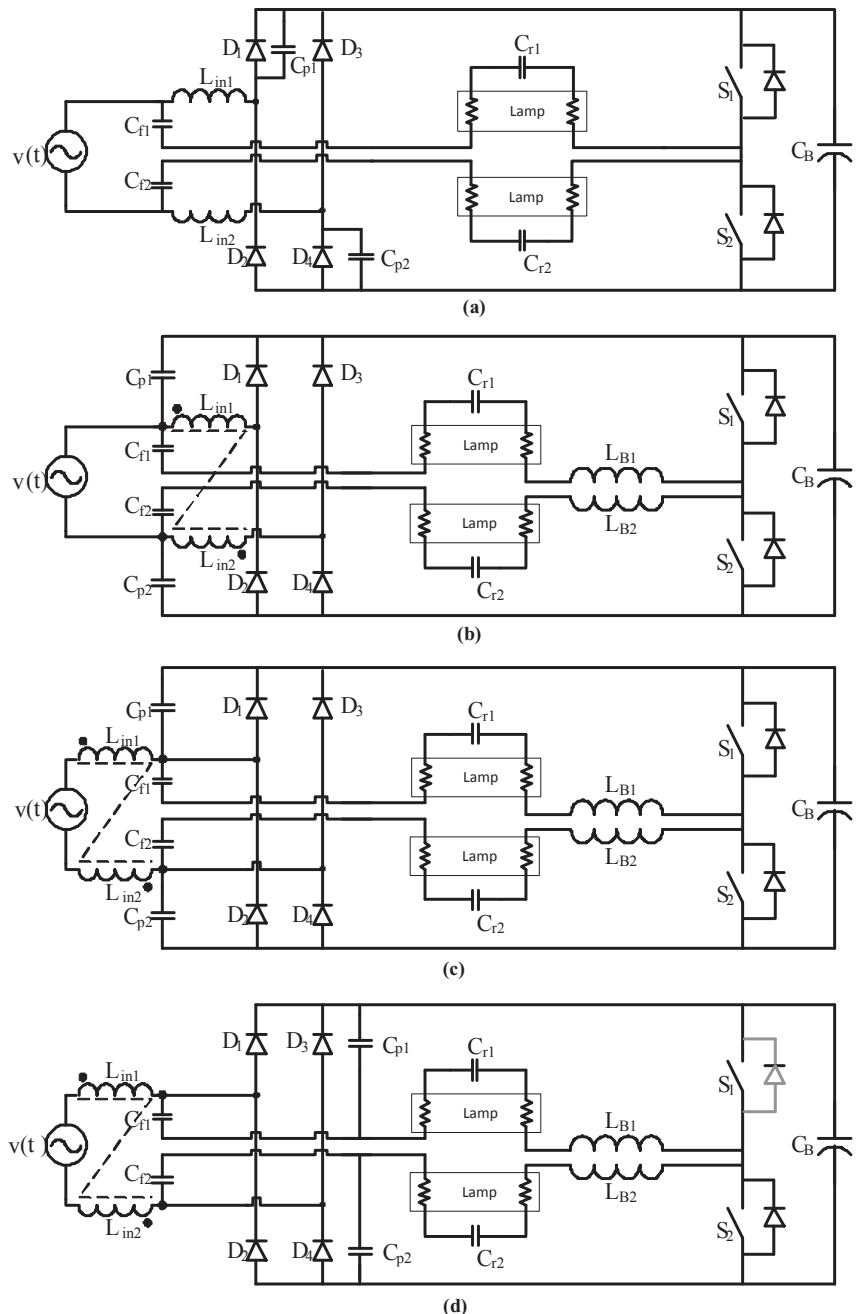

Fig. 3. Proposed topologies 2: (a) without capacitors $C_{\mathrm{d} 1}$ and $C_{\mathrm{d} 2}$, without $L C$ input filter, and without ballast inductors $L_{\mathrm{B} 1}$ and $L_{\mathrm{B} 2}$; (b) without $L C$ filter and with boost inductors $L_{\mathrm{in} 1}$ and $L_{\mathrm{in} 2}$ coupled; (c) without boost inductors $L_{\mathrm{in} 1}$ and $L_{\mathrm{in} 2}$ and without input filter capacitors $C_{\mathrm{f}}$; (d) Topology variation from Fig. 3(c). 
All the circuits presented in Figs. 2 and 3 exhibit very similar performance characteristics. The main advantages are the high efficiency and low crest factor in the lamp and high input power factor. Every proposed structure can be applied with output power up to $250 \mathrm{~W}$. However, by having a fairly small number of components, they are much viable in the use of compact fluorescent lamps with power less than $40 \mathrm{~W}$.

\section{STEADY-STATE ANALYSIS}

As the way in which the circuit operates in the positive and negative semicycles are the same, and owing to the circuit symmetry in a switching period at high frequency, only half of the entire set of steps in a switching cycle of the positive semicycle is presented.

During the description of the steps of operation and the mathematical model, the following simplifications were considered for the circuit analysis:

The ripple in the bus DC voltage $V_{\mathrm{B}}$ (DC-link $C_{\mathrm{B}}$ ) will be disregarded;

The voltage over the power supply $(v(t))$ will be considered constant during a switching period, since the switching frequency is much higher than the mains frequency;

The input current will be considered constant during the whole switching period;

The resonant circuits currents will be considered as ideal current sources;

All the components will be considered ideal.

Stage $1-\left(t_{\mathrm{B} 0} \sim t_{\mathrm{B} 1}\right)$ : In the previous step, diodes $D_{1}$ and $D_{4}$ were conducting together with $t_{1}$. At $t_{0}$, the current across $L_{\mathrm{in} 2}$ reverses its direction causing the flow of current through capacitor $C_{\mathrm{P} 1}$.

Stage 1 initiates exactly when the current across $C_{\mathrm{B}}$ reaches zero, driving $D_{4}$ to off-state naturally. From this point ahead, a charge variation in $C_{\mathrm{p} 1}$ starts, resulting in a voltage reduction in its terminals. As the voltage across the capacitors $C_{\mathrm{f} 1}$ and $C_{\mathrm{f} 2}$ are constant during the switching period, the voltages across $L_{\mathrm{in} 1}$ and $L_{\mathrm{in} 2}$ change according to voltage over the capacitor $C_{\mathrm{p} 1}$, causing these elements to resonate. This step ends when $S_{1}$ is turned off and $S_{2}$ is turned on.

Stage $2-\left(t_{1} \sim t_{2}\right)$ : At $t_{1}, S_{2}$ is turned on. As currents across inductors $L_{\mathrm{in} 1}$ and $L_{\mathrm{in} 2}$ does not vary immediately, diode $D_{\mathrm{T} 2}$ starts conduction of the load current together with capacitor $C_{\mathrm{B}}$, which exhibits an instantaneous increase in current. The current across $L_{\mathrm{in} 2}$ and $C_{\mathrm{p} 1}$ reverts its direction again, rising the voltage across the $C_{\mathrm{p} 1}$ terminals.

This step ends when the current across the load reaches zero and the voltage at $C_{\mathrm{p} 1}$ reaches its clamping value $V_{\mathrm{B}}$, driving $D_{4}$ that goes into conduction.

Stage $3-\left(t_{2} \sim t_{3}\right)$ : At $t_{2}$, the current across the load exchange direction and diode $D_{4}$ is driven to on-state. In this step, voltages in $C_{\mathrm{p} 1}$ and $C_{\mathrm{p} 2}$ are clamped, equal to $V_{\mathrm{B}}$, and the currents across diodes $D_{1}$ and $D_{4}$ fall and rise, respectively, according to charge variation at $C_{\mathrm{B}}$. This step ends when the current across $C_{\mathrm{B}}$ reaches zero and $D_{1}$ stops to conduct naturally.

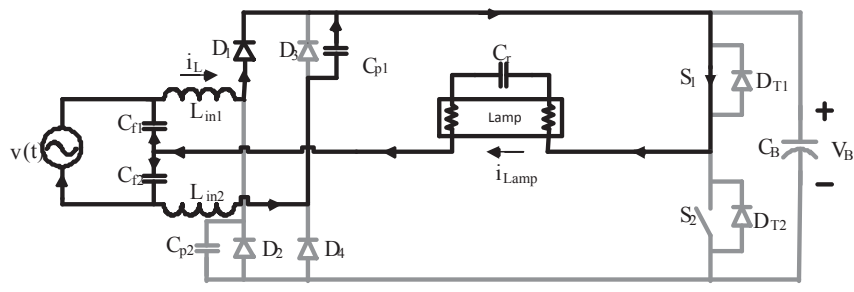

Fig. 4. Operating stage $1\left(t_{0}-t_{1}\right)$.

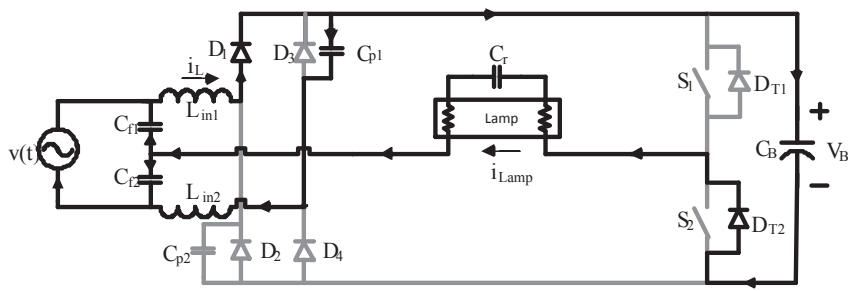

Fig. 5. Operating stage $2\left(t_{1}-t_{2}\right)$.

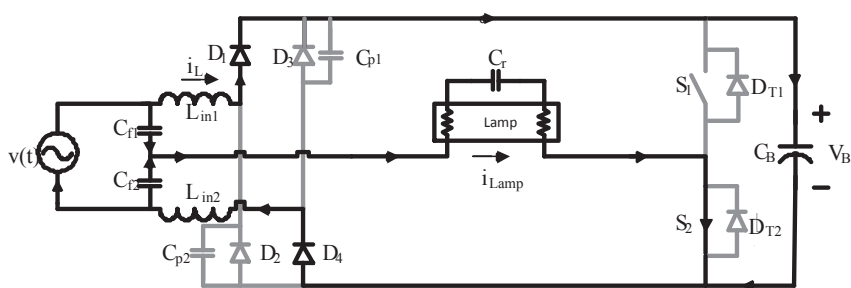

Fig. 6. Operating stage $3\left(t_{2}-t_{3}\right)$.

The theoretical waveforms in steady-state of a switching period from the steps previously described are presented in Figure 7.

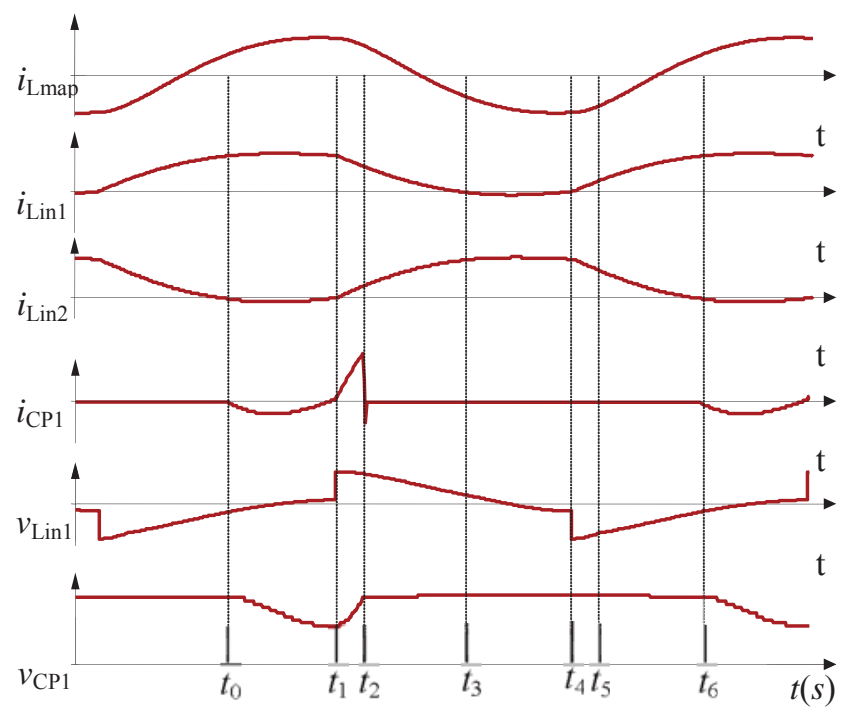

Fig. 7. The theoretical waveforms in steady-state of a switching period.

\section{DESIGN CONSIDERATIONS}

The mathematical analysis is carried out through observation of operating steps, which represents the electronic ballast principles of operation. From the mathematical analysis, it is possible to define the main parameters of the presented electronic ballast. It is evident that there is no need to analyze all the steps, because some are repetitive, and therefore, does not influence the calculated 
results. Thus, only steps from $t_{0}$ to $t_{3}$ will be discussed. In this interval, the charge of the capacitor $C_{\mathrm{p} 1}$ varies, allowing definition of equations in these steps to determine the values of the inductors $L_{\mathrm{in} 1}$ and $L_{\mathrm{in} 2}$, along with the values of capacitors $C_{\mathrm{p} 1}$ and $C_{\mathrm{p} 2}$. As the charge variation in the capacitor $C_{\mathrm{p} 1}$ is identical to that in $C_{\mathrm{p} 2}$, it is needless to reproduce the analysis for the time interval where such variation occurs. Therefore, equations that define $C_{\mathrm{p} 1}$ and $C_{\mathrm{p} 2}$ are the same, similar to those that define $L_{\mathrm{in} 1}$ and $L_{\mathrm{in} 2}$.

\section{A. Considerations:}

$$
\begin{gathered}
v(t)=V_{\mathrm{P}} \sin (\omega t) \\
i_{\text {Lamp }}(t)=I_{\text {PLamp }} \sin \left(\omega_{\mathrm{s}} t+\theta\right) \\
L_{\mathrm{in} 1}=L_{\mathrm{in} 2}=\frac{L}{2} \\
C_{\mathrm{p} 1}=C_{\mathrm{p} 2}=C \\
i_{\mathrm{L}}(t)=i_{\text {Lin } 1}(t)
\end{gathered}
$$

B. Interval $t_{0}-t_{2}$ :

$$
\begin{gathered}
i_{\mathrm{L}}(t)=I_{\text {Lamp }} \sin (\theta) \cos \left(\omega_{0} t\right)+ \\
+\left(\frac{|v(t)|-V_{\mathrm{B}}}{z_{0}}\right) \sin \left(\omega_{0} t\right)+K
\end{gathered}
$$

Where $V_{\mathrm{B}}$ is the capacitor $C_{\mathrm{B}}$ voltage, $I_{\mathrm{Lamp}}$ is defined as

and

$$
I_{\text {Lamp }}=\left(1-\frac{C L}{2} \omega_{\mathrm{s}}^{2}\right) I_{\text {PLamp }}
$$

$$
\omega_{0}=\frac{1}{\sqrt{C L}}, \quad C=\frac{1}{Z_{0} \omega_{0}} \text { e } Z_{0}=\sqrt{\frac{L}{C}}
$$

with

$$
\omega_{\mathrm{s}}=2 \pi f_{\mathrm{s}} \text { and } T_{\mathrm{s}}=\frac{1}{f_{\mathrm{s}}}
$$

Where $f_{\mathrm{s}}$ is the switching frequency of the inverter stage, and

$$
\begin{gathered}
K=\frac{\omega_{0}^{2}}{\omega_{0}^{2}-\omega_{\mathrm{s}}^{2}} I_{\text {Lamp }}\left[\sin \left(\omega_{\mathrm{s}} t+\theta\right)-\sin (\theta) \cos \left(\omega_{0} t\right)\right]- \\
-\frac{\omega_{0}^{2}}{\omega_{0}^{2}-\omega_{\mathrm{s}}{ }^{2}} I_{\text {Lamp }}\left[\frac{\omega_{\mathrm{s}}}{\omega_{0}} \cos (\theta) \sin \left(\omega_{0} t\right)\right]
\end{gathered}
$$

C. Interval $t_{2}-t_{3}$ :

$$
i_{\mathrm{L}}(t)=\frac{|v(t)|-V_{\mathrm{B}}}{L}\left(t-t_{2}\right)+i_{\mathrm{L}}\left(t_{2}\right)
$$

1. Average $i_{L}(t)$ current is

$$
i_{\text {Lmed }}=\frac{1}{T_{\mathrm{s}}} \int_{t_{0}}^{t_{2}} i_{\mathrm{L}}(t) d t+\frac{1}{T_{\mathrm{s}}} \int_{t_{2}}^{t_{3}} i_{\mathrm{L}}(t) d t
$$

Considering that

$$
\alpha=\frac{\omega_{0}}{\omega_{\mathrm{s}}} ; \quad t=\frac{\varphi}{\omega_{\mathrm{t}}} ; \quad \rightarrow d t=\frac{d \varphi}{\omega_{\mathrm{t}}} ; \omega_{\mathrm{s}} T_{\mathrm{s}}=2 \pi
$$

Aproximating

$$
t_{2}=\frac{T_{\mathrm{s}}}{3}, \quad t_{3}=\frac{T_{\mathrm{s}}}{2} \quad \text { e } i_{\mathrm{L}}\left(t_{2}\right)=I_{\mathrm{P}}=2 \frac{P_{\text {out }}}{V_{\mathrm{P}}}
$$

where $\mathrm{P}_{\text {out }}$ is the average power lamp, yelds

$$
\begin{aligned}
& I_{\text {Lamp }}=\frac{\pi\left(\alpha^{2}+1\right)}{\alpha^{2}}\left[V_{\mathrm{B}}\left(\frac{1}{72 L f_{\mathrm{s}}}+\frac{1-\cos (\alpha \pi)}{2 \pi \alpha Z_{0}}\right)-\right. \\
& \left.-\frac{P_{\text {out }}}{3 V_{\mathrm{P}}}-\left(\frac{1}{2 \pi} \frac{1}{\alpha^{2}-1} I_{\text {Lamp }}\right)(1-\cos (\alpha \pi))\right]
\end{aligned}
$$

$$
V_{B}=\frac{\left[\frac{1 \alpha^{2}}{\pi \alpha^{2}-1} I_{\text {Lamp }}+\left(\frac{1}{2 \pi} \frac{1}{\alpha^{2}-1} I_{\text {Lamp }}\right)(1-\cos (\alpha \pi))+\frac{P_{\text {out }}}{3 V_{P}}\right]}{\frac{T_{S}}{72 L}+\frac{1-\cos (\alpha \pi)}{2 \pi \alpha Z_{0}}}
$$

2. Design considerations:

$$
\begin{gathered}
P_{\text {in }}(t)=|v(t)| \cdot i_{\mathrm{g}}(t) \\
P_{\text {in }}(t)=|v(t)|^{2}\left[\frac{T_{S}}{72 L}+\frac{1-\cos (\alpha \pi)}{2 \pi \alpha Z_{0}}\right]
\end{gathered}
$$

Considering that average power output is

$$
P_{\text {out }}=\eta P_{\text {in }}
$$

where $\eta$ is the efficiency and $P_{\text {in }}$ is the average power input and

yelds

$$
\omega_{0}=\frac{1}{\sqrt{C L}}=\alpha \omega_{\mathrm{s}}
$$

and

$$
C=\left(\frac{2 P_{\text {out }}}{\eta V_{\mathrm{P}}^{2} f_{\mathrm{s}}}-\frac{1}{72 L f_{\mathrm{s}}^{2}}\right) \frac{1}{1-\cos (\alpha \pi)}
$$

$$
L=\frac{\eta V_{\mathrm{P}}^{2}}{8 P_{\text {out }} f_{\mathrm{s}}}\left[\frac{1-\cos (\alpha \pi)}{\pi^{2} \alpha^{2}}+\frac{1}{18}\right]
$$

Figure 8 shows a surface that describes the value of $C$ as a function of $f_{\mathrm{s}}$ and $P_{\text {out }}$. It is remarkable that the values of $C$ are inversely proportional to $f_{\mathrm{s}}$ and directly proportional to $P_{\text {out }}$.

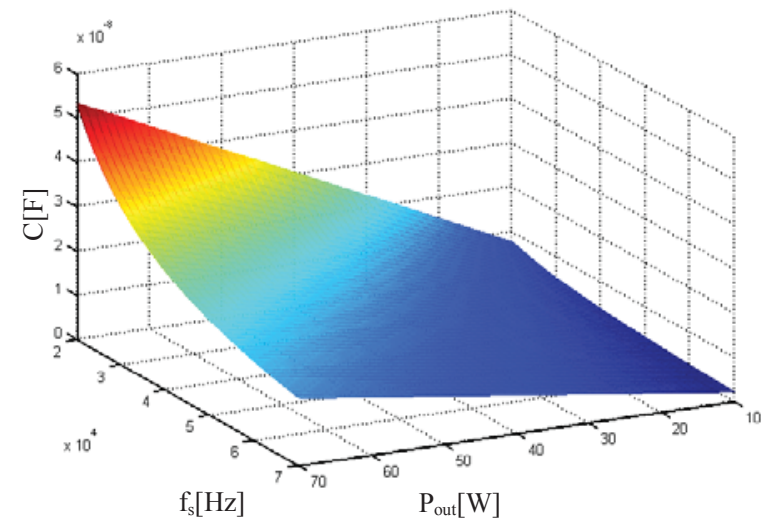

Fig. 8. Variation of $C_{\mathrm{P}}$ as a function of lamp power $P_{\text {out }}$ and switching frequency $f_{\mathrm{s}}$.

The surface shown in Figure 9 demonstrates that as the switching frequency and lamp power increase, the boost inductor $L_{\text {in }}$ tends to decrease. These data are important in applications where more compact structures are necessary, as in the case of fluorescent lamps.

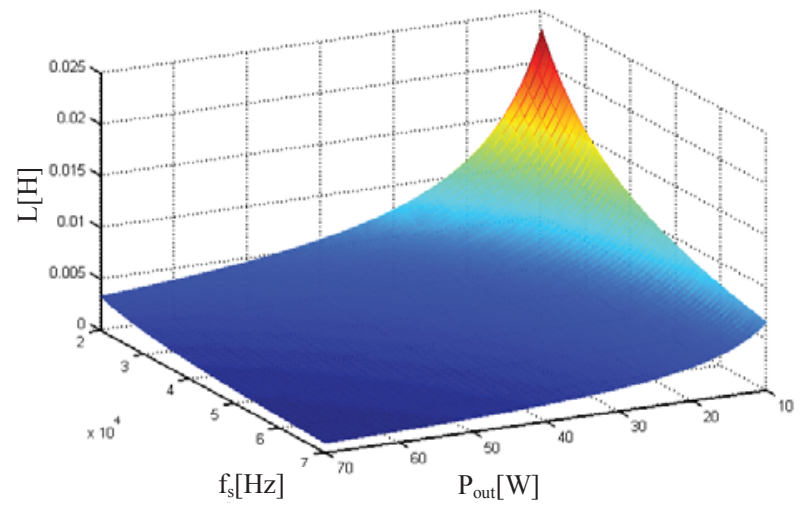

Fig. 9. Variation of $L_{\text {in }}$ as a function of lamp power $P_{\text {out }}$ and switching frequency $f_{\mathrm{s}}$. 


\section{EXPERIMENTAL RESULTS}

To achieve the desired experimental results, one prototype using a self-oscillating drive was implemented to verify the design methodology applied to the electronic ballast proposed in Figure 2(c), where a 26W PL-type lamp was used. Figure 10 presents the implemented prototype

Although not all standards require power-factor correction, this work aims to demonstrate the technical viability of the structure under low-power applications, when compared with other electronic ballast structures having power-factor correction.

The parameters used in the calculation of the circuit elements are: switching frequency of $50 \mathrm{kHz}$, peak input voltage of $311 \mathrm{~V}$ sinusoidal, efficiency of $90 \%$, and $\alpha=0.6$ [13].

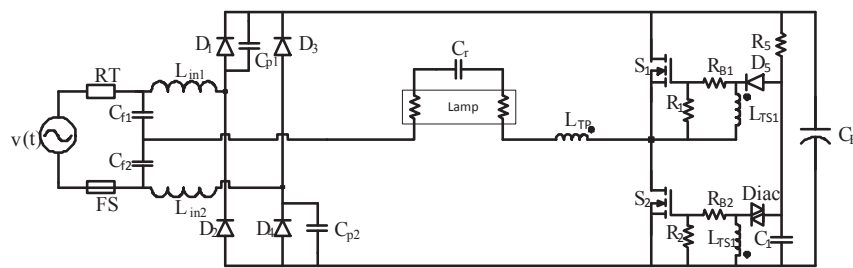

Fig. 10. Diagram of the implemented prototype for $26 \mathrm{~W}$ Lamp.

According to the derived equations in the mathematical analysis, the values for the electronic ballast prototype can be obtained. Table I present the implemented design parameters.

TABLE I

\begin{tabular}{cc}
\multicolumn{2}{c}{ Implemented design parameters } \\
\hline Parameters & Value \\
\hline $\mathrm{L}_{\mathrm{in} 1}=\mathrm{L}_{\mathrm{in} 2}$ & $2 \mathrm{mH}$ \\
\hline $\mathrm{C}_{\mathrm{p} 1}=\mathrm{C}_{\mathrm{p} 2}$ & $6.8 \mathrm{nF}$ \\
\hline $\mathrm{C}_{\mathrm{r}}$ & $5.4 \mathrm{nF}$ \\
\hline $\mathrm{C}_{\mathrm{f} 1}=\mathrm{C}_{\mathrm{f} 2}$ & $330 \mathrm{nF}$ \\
\hline $\mathrm{R}_{\mathrm{B} 1}=\mathrm{R}_{\mathrm{B} 2}$ & $33 \Omega$ \\
\hline $\mathrm{R}_{1}=\mathrm{R}_{2}$ & $1 \mathrm{~K} \Omega$ \\
\hline $\mathrm{C}_{\mathrm{B}}$ & $33 \mu \mathrm{F} / 450 \mathrm{~V}$ \\
\hline $\mathrm{D}_{1}=\mathrm{D}_{2}=\mathrm{D}_{3}=\mathrm{D}_{4}$ & $1 \mathrm{~N} 4937$ \\
\hline $\mathrm{D}_{5}$ & $1 \mathrm{~N} 4936$ \\
\hline $\mathrm{S}_{1}=\mathrm{S}_{2}$ & $\mathrm{IRF} 840$ \\
\hline $\mathrm{R}_{5}$ & $470 \mathrm{k} \Omega$ \\
\hline
\end{tabular}

The experimental results obtained are presented in the TABLE II.

TABLE II

Experimental results obtained

\begin{tabular}{cc}
\hline Parameters & Value \\
\hline $\mathrm{P}_{\text {in }}$ & $25.1 \mathrm{~W}$ \\
\hline $\mathrm{P}_{\text {out }}$ & $22.67 \mathrm{~W}$ \\
\hline $\mathrm{V}_{\mathrm{B}}$ & $\begin{array}{c}448 \mathrm{~V} \text { (maximum } \\
\text { voltage) }\end{array}$ \\
\hline $\mathrm{H}$ & $90.3 \%$ \\
\hline $\mathrm{THD}$ & $6.1 \%$ \\
\hline Power Factor & 0.996 \\
\hline Crest Factor & 1.52
\end{tabular}

The AC input voltage and current, which tends to be sinusoidal, are presented in Figure 11(a). Remarkably, the electronic ballast complies with the established limits in the standard. To completely eliminate the high-frequency harmonics and the Electromagnetic Interference (EMI) problems, a small filter inductor is used in the electronic ballast input. The AC input voltage and current using an input $L_{\mathrm{f}}$ filter are presented in Figure 11(b). The lineharmonic components (with Total Harmonic Distortion -
THD $=6,1 \%$, , in accordance to the limits established by standard IEC 61000-3-2 for Class C lighting applications, are presented in Figure 12.

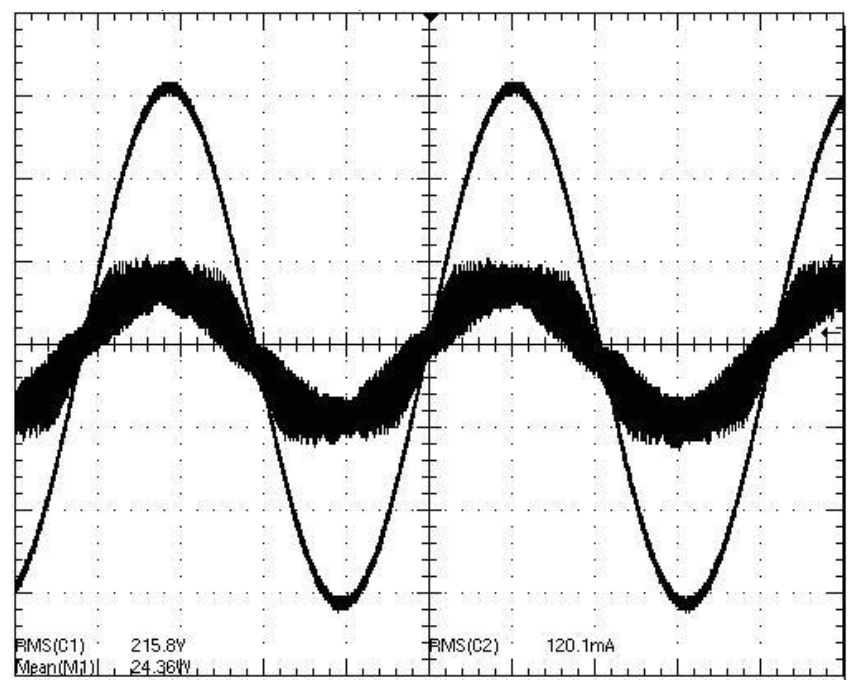

(a)

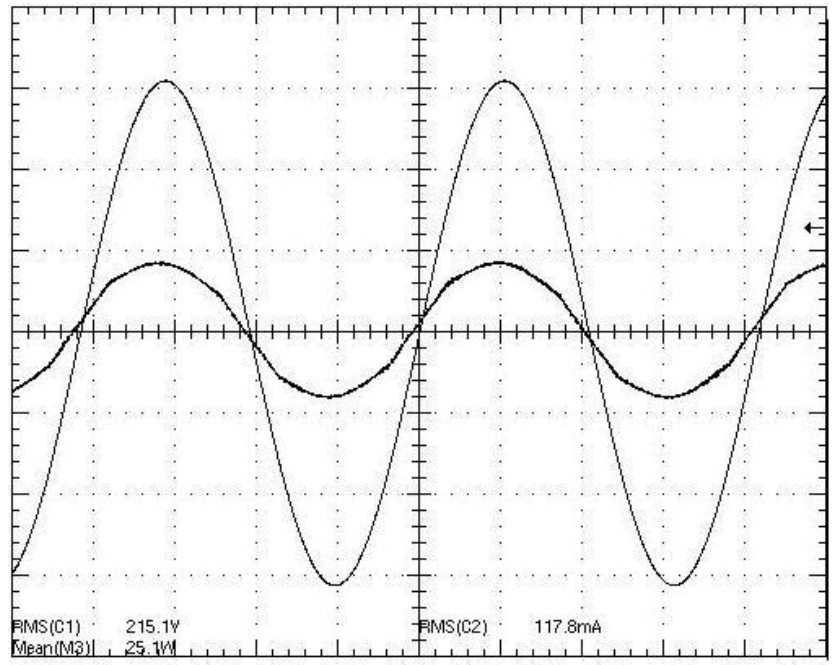

(b)

Fig. 11. (a) Supply voltage and current ( $t: 4 \mathrm{~ms} / \operatorname{div} ; v: 100 \mathrm{~V} / \operatorname{div} ; i$ : $200 \mathrm{~mA} /$ div). (b) Supply voltage and current with input inductor $L_{\mathrm{f}}$ filter $\left(L_{\mathrm{f}}=200 \mu \mathrm{H}\right)(t: 4 \mathrm{~ms} / \mathrm{div} ; v: 100 \mathrm{~V} / \mathrm{div} ; i: 200 \mathrm{~mA} / \mathrm{div})$.

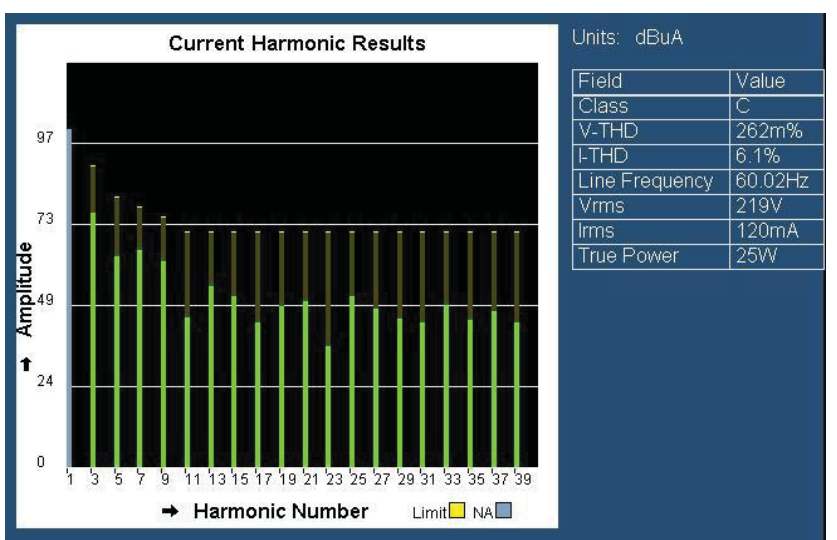

Fig. 12. Supply current harmonics, according to IEC61000-3-2 Class C. 
The crest factor measured over the lamp is 1.525 , which represents a satisfactory condition, taking into account the limit of 1.7 established in the standard ANSI C82.11, as can be observed in Figure 13. Through Figure12 (True Power) and Figure 13 it can observed that the obtained efficiency is $90 \%$. Figure 14 presents the voltage, current and power of the lamp in high frequency. It can be observed which the waveforms tend to be sinusoidal. Figure 15 presents the lamp startup and it can observe that is of instantaneous type. As the structure has a self-oscillating drive and is devoid of integrated circuits, the application of programmed preheating becomes a complex task, because one of the main targets of this structure is the reduction in production costs. This was possible owing to the smooth on-state switching of the transistors, as shown in Figure 16.

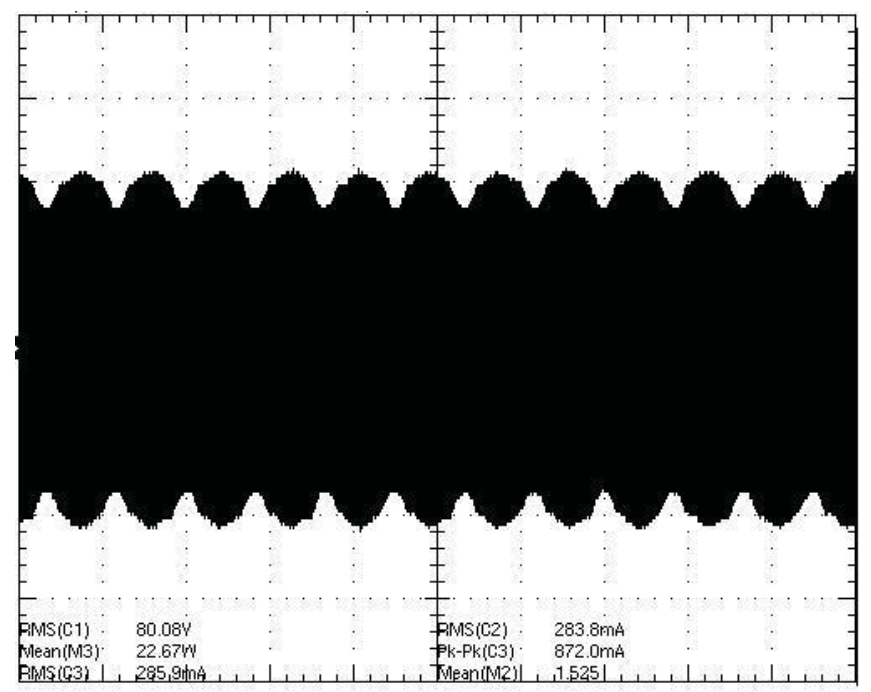

Fig. 13. Current across the lamp with crest factor equal to $1.525(t$ : $10 \mathrm{~ms} /$ div; $i: 200 \mathrm{~mA} / \mathrm{div})$.

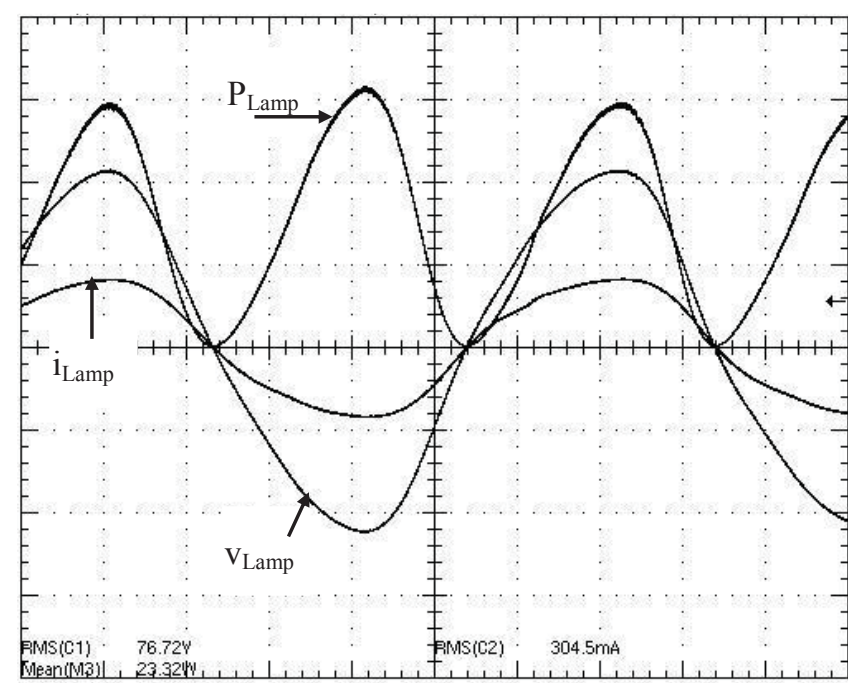

Fig. 14. Voltage, current, and power on the lamp ( $t: 4 \mu \mathrm{s} /$ div; $v: 50$ V/div; $i$ : $500 \mathrm{~mA} /$ div; $P: 15 \mathrm{~W} /$ div).

\section{CONCLUSION}

A new family of electronic ballasts for fluorescent lamps has been presented. Using concepts known as the charge pump concept, new structures were obtained, where there is no necessity to use the ballast inductor to limit and stabilize the lamp current, because the boost inductor works a dual role, performing these functions and making power-factor correction.

The withdrawal of the ballast inductor provides the reduction in the number of components, and consequently, weight, volume, and cost. The main features of the CIC electronic ballasts were preserved, such as the high power factor, but a significant improvement in efficiency and crest factor could be observed. The experimental results of the implemented structure show that the electronic ballast has high possibilities of market deployment of compact fluorescent lamps with power-factor correction, because it complies with the IEC 61000-3-2 Class C standard, keeping the limit of the crest factor. In addition, it was also verified that there is no restriction in the use of a self-oscillating drive.

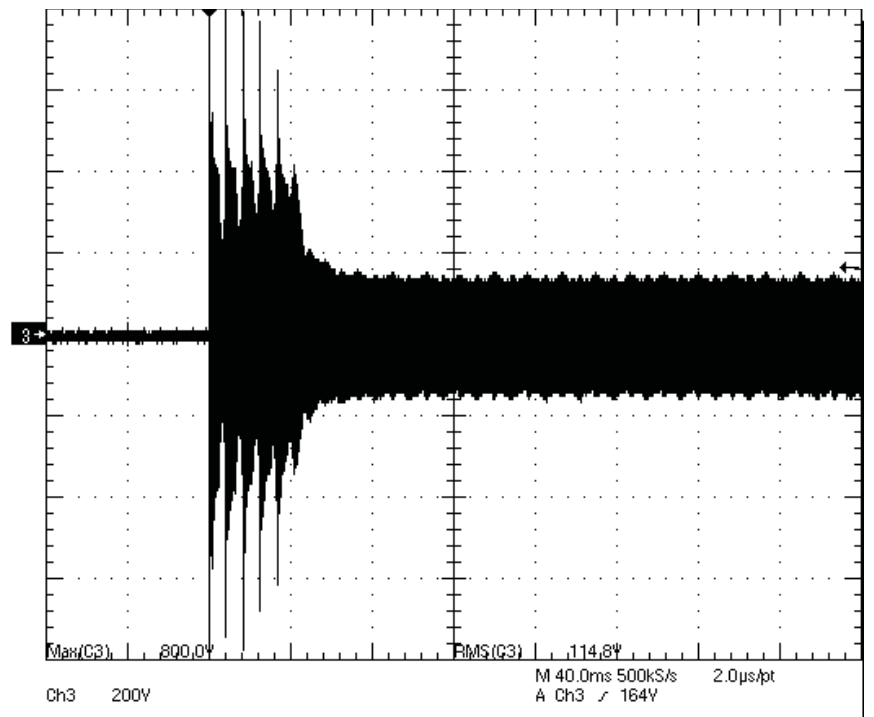

Fig. 15. Startup voltage on the lamp ( $t: 40 \mathrm{~ms} / \mathrm{div} ; v: 200 \mathrm{~V} / \mathrm{div})$.

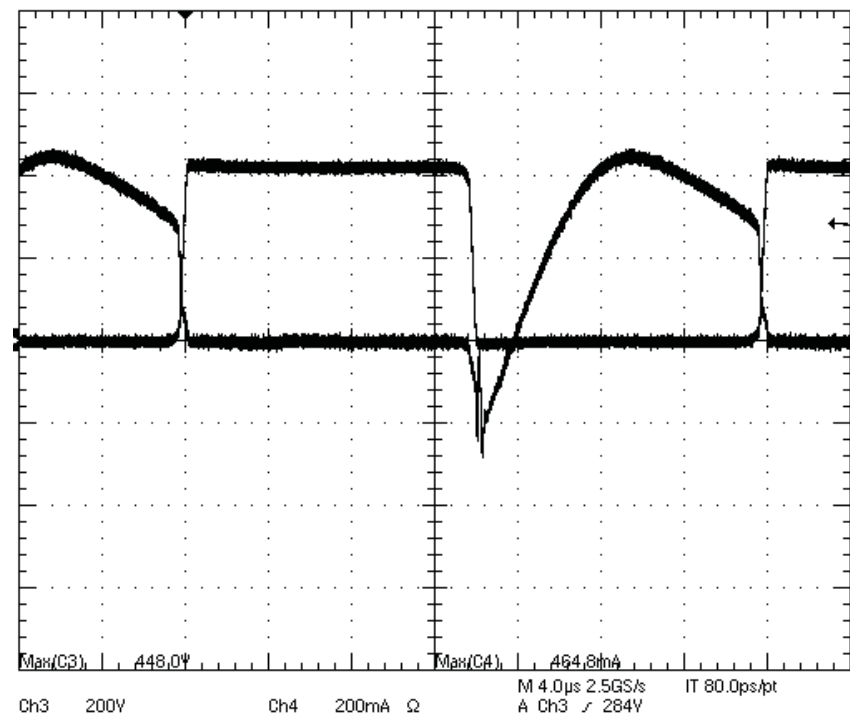

Fig. 16. Voltage and current on the switch during switching ( $t: 4$ $\mu \mathrm{s} /$ div; $v: 200 \mathrm{~V} /$ div; $i: 200 \mathrm{~mA} /$ div). 


\section{REFERENCES}

[1] B. Mammano, "Improving Power Supply Efficiency The Global Perspective", SEM1700 2006-2007 Power Supply Design Seminar, Texas Instruments inc., 20062007, pp. 1-1 through 1-9.

[2] L. Brush, "Power Factor Correction Market Driven by Regulations", Bodo's Power, 2006.

[3] B. Sharifipour, J. S. Huang, P. Liao, L. Huber, M. M. Jovanovic, "Manufacturing and Cost Analysis of PowerFactor-Correction Circuits", IEEE Applied Power Electronics Conference and Exposition, APEC '98, pp. 490-494, 1998.

[4] W. F. Ray, R. M. Davis, "The Definition and Importance of Power Factor for Power Electronic Converters", Proc. European Conference on Power Electronics and Applications (EPE), pp. 799 - 805, 1989.

[5] J. A. Alves, A. J. Perin, I. Barbi, "An Electronic Ballast with High Power Factor for Compact Fluorescent Lamp", IEEE Industry Application Society - Annual Meeting, pp. 2129 - 2135, 1996.

[6] C. S. Moo, K. H. Lee, Cheng, H. L. W. M. Chen, “A. Single-Stage High-Power-Factor Electronic Ballast With ZVS Buck-Boost Conversion", IEEE Transactions on Industrial Electronics, vol. 56, no. 4, pp. 1136 - 1146 , 2009.

[7] C. Ekkaravarodome, A, Nathakaranakule, I. Boonyaroonate, "Single-Stage Electronic Ballast Using Class-DE Low-d/dt Current-Source Driven Rectifier for Power-Factor Correction", IEEE Transactions on Industry Applications, 2010.

[8] J. C. Hsieh, J. L. Lin, "Novel Single-Stage SelfOscillating Dimmable Electronic", IEEE Transactions on Industry Applications, 2009.

[9] J. Qian, F. C. Lee, "Charge Pump Power - Factor Correction Technologies Part I: Concept and Principle", IEEE Transactions on Power Electronics, vol. 15, no. 1, pp. $121-129,2000$.

[10]C. B. Nascimento, A. J. Perin, "High Power Factor Electronic Ballast for Fluorescent Lamps with Reduced Input Filter and Low Cost of Implementation", IEEE Transactions on Industrial Electronics, Vol. 55, No. 2, pp. $711-721,2008$.

[11]J. Qian, F. C. Lee, “A New Continuous Input Current Charge Pump Power Factor Correction (CIC-CPPFC) Electronic Ballast", IEEE Industry Application Society Annual Meeting, pp. 2299 - 2306, 1997.

[12]M. S. Moisin, et al, "Ballast Circuit for Fluorescent Lamp", United States Patent 5.691.606, 1997.

[13]E. I. Pereira, C. B. Nascimento, A. J. Perin, "Electronic ballast for fluorescent lamps with the PFC stage integraded with the resonant inverter", 35th Annual IEEE Power Electronic Specialists Conference, pp. 4050 - 4056, 2004.

[14]C. B. Nascimento, E. I. Pereira, A. J. Perin, "Low Cost High Factor Electronic Ballast with no Input Filter", 36th Annual IEEE Power Electronic Specialists Conference, pp. 1100 - 1106, 2005.

[15]J. Qian, F. C. Lee, "Charge Pump Power - Factor Correction Technologies Part II: Ballast Applications",
IEEE Transactions on Power Electronics, vol. 15, no. 1, pp. $130-139,2000$.

[16]R. L. Lin, H. Y. Liu, H. M. Shih, "AC-Side CCMCSCP-PFC Electronic Ballast", IEEE Transactions on Power Electronics, vol. 22, no. 3, pp. 789 - 796, 2007.

[17]W. Paul, T. Satoshi, "Light's Labour's Lost: Policies for Energy-Efficient Lighting", International Energy Agency, pp. 25-30, 2006.

[18]I. Takahashi, "Power Factor Improvement of a Diode Rectifier Circuit by Dither". In Conf. Rec. IEEE-IAS Annual Meeting, p. 1289 - 1294, 1990.

[19]T. F. Wu, C. H. Chang, Z. R. Liu, "Ripple-Free, SingleStage Electronic Ballasts with Dither-Booster Power Factor Corrector", IEEE Industry Applications Society, pp. $2372-2379,1997$.

\section{BIOGRAPHIES}

Claudinor B. Nascimento was born in Tubarão, Santa Catarina, Brazil, in 1971. He received the B.E., M.S., and Ph.D. degrees in electrical engineering from Universidade Federal de Santa Catarina, Florianópolis, Brazil, in 1994, 1996, and 2005, respectively. He joined the Electronic Departament at Universidade Tecnológica Federal do Paraná, Ponta Grossa, Brazil, in 1997, where he is currently Professor of Power Electronics and Automation and Control. $\mathrm{He}$ is currently the Coordinator of Postgraduate Program in Electrical Engineering, Campus of Ponta Grossa, where he was engaged in education and research on power electronics. His research interests include lighting system, power-factorcorrection circuits and new converter topologies.

Marcos Aurélio Izumida Martins was born in Maringá, Paraná, Brazil, in 1971. He received the B.E. and M.S. degrees in Electrical Engineering from Universidade Federal de Santa Catarina, Florianópolis, Brazil, in 2005 and 2006, respectively. He joined the Electrical Projects Department at Reivax - Control and Automation as Design Engineer of Hydroelectric Power Plants Automation, Protection and Regulation, Florianópolis, Brazil, in 2006. He is currently Site Manager of Substation Plants at Toshiba Infrastructure South America. His interests include lighting system, powerfactor-correction, power system stabilization, static var compensation, substations, transmission lines and power plants infrastructure management.

Mauricio dos Santos Kaster was born in Maringá, Paraná, Brazil, in 1968. He received the Bachelor degree in Electrical Engineering by Universidade Federal do Paraná in 1992, Master in Industrial Informatics by Centro Federal de Educação Tecnológica do Paraná in 1996 and $\mathrm{PhD}$ in Automation and Systems by Universidade Federal de Santa Catarina in 2006. Actually he is professor at Universidade Tecnológica Federal do Paraná, campus Ponta Grossa, and participates in the post-graduate programs in Electrical Engineering in the campuses of Ponta Grossa and Cornélio Procópio. His interests include nonlinear control systems, power electronic converters, sliding-mode control, digital control systems, microcontrollers and FPGA devices. 
Arnaldo José Perin was born in Nova Prata, Rio Grande do Sul, Brazil. He received the B.E. degree in Electronic Engineering from the Pontifícia Universidade Católica do Rio Grande do Sul, Brazil in 1977, the M. Sc. degree in Electrical Engineering from Universidade Federal de Santa Catarina (UFSC), Florianopolis, SC, Brazil in 1980. In 1984 he received the Doctor of Engineering degree (Dr. Eng.) from the Institut National Polytechnique de Toulouse (INPT), Toulouse, France. $\mathrm{He}$ joined the Electrical
Engineering Department at UFSC in 1980 where he was engaged in education and research on power electronics until 2009. After that he assumed a volunteer professorship with the Electrical Engineering Graduation Program at UFSC. His research interests include power electronics, modulation, AC converters and power factor correction. Dr. Perin is currently a member of the Brazilian Power Electronics Society (SOBRAEP) and of the IEEE. 